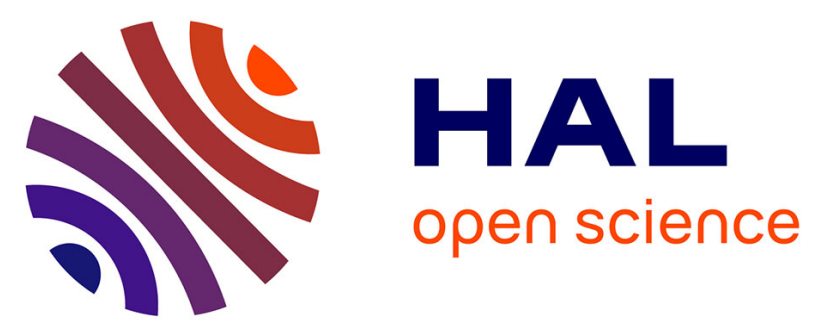

\title{
Remote Actuation of a Light-Emitting Device Based on Magnetic Stirring and Wireless Electrochemistry
}

\author{
Alice L. Dauphin, Stéphane Arbault, Alexander Kuhn, Neso Sojic, Laurent
}

Bouffier

\section{- To cite this version:}

Alice L. Dauphin, Stéphane Arbault, Alexander Kuhn, Neso Sojic, Laurent Bouffier. Remote Actuation of a Light-Emitting Device Based on Magnetic Stirring and Wireless Electrochemistry. ChemPhysChem, 2020, 21 (7), pp.600-604. 10.1002/cphc.202000019 . hal-02510411

\author{
HAL Id: hal-02510411 \\ https://hal.science/hal-02510411
}

Submitted on 14 Sep 2020

HAL is a multi-disciplinary open access archive for the deposit and dissemination of scientific research documents, whether they are published or not. The documents may come from teaching and research institutions in France or abroad, or from public or private research centers.
L'archive ouverte pluridisciplinaire HAL, est destinée au dépôt et à la diffusion de documents scientifiques de niveau recherche, publiés ou non, émanant des établissements d'enseignement et de recherche français ou étrangers, des laboratoires publics ou privés. 


\section{Remote actuation of a light-emitting device based on magnetic stirring and wireless electrochemistry}

Alice Dauphin, Stéphane Arbault, Alexander Kuhn, Neso Sojic, Laurent Bouffier*

We propose a straightforward access to a dynamic light-emitting device powered by wireless electrochemistry. A magnetic stirrer rotates a light-emitting diode (LED) due to the intrinsic magnetic properties of the tips that contain iron. At the same time, the LED is submitted to a steady-state electric field. The resulting variation of the LED alignement enables an alternating light emission that is controlled by the rotation rate. The continuous stirring also ensures a continuous mixing of the electrolyte that improves the stability of the output signal.

Bipolar electrochemistry (BPE) has encountered a strong renewal of interest during the last two decades. To date, an increasing number of applications in analytical chemistry and materials science were already proposed.1-8 For example, the design of tailored surface gradients or particles, single cell-capture devices, polymer light-emitting electrochemical cells and various analytical platforms were proposed.9-15 Analytical approaches based on BPE very often involve metal electrodes (like Pt, $\mathrm{Au}$, or $\mathrm{Ag}$ ) that are screen-printed on glass and integrated inside a microchannel.4,6 Therefore, the corresponding fabrication process requires access to a suitable manufacturing facility that can be time-consuming. Recently, several paper-based strategies were proposed in an effort towards lowcost sensors.16-21 However, high-precision manufacturing remains essential in most of these approaches based on lab-on-chip devices. Here, we report an original and extremely simple strategy that, in addition to the power supply, does only involve a commercial light-emitting diode (LED) combined with a magnetic stirrer. A continuous voltage is applied to the solution while the LED is spinning, resulting in an alternating light emission that is observed once per turn when the LED is properly aligned alongside the electric field lines (Scheme 1).

It is noteworthy that rotating bipolar electrodes have already been described in the past. Electric field-induced rotation was obtained by the site-selective generation of gas bubbles on an engineered bipolar electrode mounted on a rotation axis.22,23 Alternating light emission produced by electrogenerated chemiluminescence was also reported with a bipolar electrode that was mechanically actuated by a rotor.24 Again, the new approach proposed here is much simpler because there is no need to design on purpose a bipolar electrode, which is here a cheap, commercially available LED (typical prize lower than $0.5 €$ per unit). Also, the electro-induced migration of charged species, which is one of the major drawbacks of BPE occurring in an open-cell configuration, is avoided due to a continuous stirring of the electrolytic solution.

The electronic characterization of the LED is given in Figure S1. The current versus potential $(\mathrm{I} / \mathrm{V})$ curve was recorded by connecting directly the LED to a voltage supply. Typically, a minimal voltage of $1.6 \mathrm{~V}$ is necessary to light up the LED with a gradual increase of brightness. The light intensity reaches $50 \%$ of its maximum value when the applied voltage is about $1.8 \mathrm{~V}$. In the context of BPE, LEDs were previously used as conventional electronic components to reveal BPE-driven reactions by a simple visual readout.25,26 We also reported recently the incorporation of a LED either in a metal or polymer-based bipolar electrode.27,28 However, the full characterization of a LED behavior under BPE conditions was never reported. The corresponding I/V curve recorded in BPE is provided in Figure 1. It was obtained by measuring the bipolar current flowing across the LED with two probes connected to a multimeter. By comparison, the overall (ionic) current is provided in Figure S2. The LED was immersed in an aqueous solution of $5 \times 10-3 \mathrm{M} \mathrm{KCl}$ with a typical distance of $180 \mathrm{~mm}$ between both gold feeder electrodes (Scheme S1 and Figure S3). The calibration curve was built by measuring the bipolar current and light intensity as a function of the applied voltage with an 
increment of $5 \mathrm{~V}$. The evolution of the light intensity with voltage shows that applying $20 \mathrm{~V}$ is necessary to light up significantly the LED. In that case, the brightness is about $30 \%$ of its maximum. A careful analysis of the images reveals that the exact threshold voltage is $15 \mathrm{~V}$ enabling a brightness of about $1 \%$ that is hardly visible with the naked eyes. This threshold voltage value is consistent with the measurement of the bipolar current that starts to flow significantly across the LED when applying $15 \mathrm{~V}$. The length of the LED, including both conducting wires, is $55 \mathrm{~mm}$ meaning that $4.58 \mathrm{~V}$ (i.e. electric field of $\sim 0.8 \mathrm{~V} \mathrm{~cm}-1$ ) is necessary to light up the LED in the BPE configuration. This value is much larger than the theoretical value calculated from the standard potential of water oxidation and proton reduction. The reason is the large over-potentials that are necessary to drive these reactions on the iron-based tips of the LED (Figure S4). One can note that the light intensity increases steadily with the voltage up to $50 \mathrm{~V}$. For further experiments, we selected an applied voltage difference of 36 $V$, which remains a moderate voltage according to I/V characteristics that afford about $75 \%$ of the LED brightness.

In the BPE cell used for this work, an input of $36 \mathrm{~V}$ corresponds to an electric field of $2.0 \mathrm{~V} \mathrm{~cm}-1$. The first series of experiments were conducted with a static diode positioned orthogonally with respect to the feeder electrodes and by applying either a DC or an AC voltage input. In the case of a DC input of $36 \mathrm{~V}$, the LED immediately switches on and the intensity remains relatively constant when the voltage is applied for a couple of seconds (Figure $2 \mathrm{~A}$ and Video $\mathrm{S} 1$ ). On the other hand, when an AC input is applied by means of BPE $(36 \mathrm{~V}, \mathrm{f}=1 \mathrm{~Hz})$, the LED does emit light alternatively (Figure $2 \mathrm{~B}$ and Video S2). Such a frequency corresponds to one flash event for a period of one second because the voltage is alternatingly switched from $0 \mathrm{~V}$ to $36 \mathrm{~V}$. A comparison of the calibration curves recorded in $D C$ and $A C$ modes reveals no significant difference in the influence of the nature of the applied voltage on the light emission efficiency (Figure S5). However, the LED is continuously powered by the $\mathrm{DC}$ input compared to the AC one. Therefore, the mean intensity depends strongly on the acquisition time that should be selected appropriately as a function of the frequency of the AC input. It is noteworthy that the signal of the LED could also be modulated by immersing a second LED in the electrolyte. If this latter is positioned head to tail with respect to the first LED, both electronic devices can be addressed stepwise by applying two successive voltage steps of $+36 \mathrm{~V}$ and $-36 \mathrm{~V}$, resulting in a continuous light emission output with an AC input (Video S3).

To the best of our knowledge, the combination of magnetic stirring and BPE remains unexplored. The chemical nature of the LED wires is a key-element in order to achieve a magnetinduced motion. In fact, most of the available LEDs have connection tips made out of iron and/or steel. Therefore, the iron content confers ferromagnetic properties enabling readily magnetic stirring. The feasibility was tested with one LED exposed again to an electric field of $2.0 \mathrm{~V} \mathrm{~cm}-1$ and the stirrer was set at $100 \mathrm{rpm}$ or $200 \mathrm{rpm}$ (Figure 3A). A rotation speed of $100 \mathrm{rpm}$ corresponds indeed to 1.6 events per second (Video S4). The time evolution of the normalized light intensity demonstrates that the maximum intensity is rather constant and typically lasts for $0.22 \pm 0.06 \mathrm{~s}$. Indeed, the variation of the LED orientation during the rotation implies a periodic change of the apparent length of the bipolar electrode. The interfacial polarization of the LED strongly depends on this orientation and a speed of 1.66 turns per second means that the angular movement describes $600^{\circ}$ per second. Under these conditions, the LED lights up when the angle $\theta$ is lower than \pm $66^{\circ}$ compared to the normal alignment $\left(\theta=0^{\circ}\right.$ corresponds to the LED positioned orthogonally with respect to the feeder electrode plates). The apparent length of the bipolar electrode is therefore cos $\left(66^{\circ}\right) \times 55 \mathrm{~mm}=22.4 \mathrm{~mm}$ corresponding thus to a minimal polarization of about $4.48 \mathrm{~V}$, taking into account the applied voltage difference and the spacing between both feeder electrodes. This value is fully consistent with the results obtained without stirring and determined from Figure 1. By comparison, the number of light emission events is twice larger at 200 rpm with about 3.66 flashes 
per second and lasts for $0.11 \pm 0.02 \mathrm{~s}$ (Video S5). Two comparable experiments were also conducted when using two LEDs positioned head to tail (Figure 3B and Videos S6-S7). This enables to double the frequency modulation and consequently to increase the number of events up to 7 per second at 200 $\mathrm{rpm}$. This latter experimental configuration permits to reach "artificially" a higher frequency rectification that is not necessarily achievable by the magnetic stirrer with one single LED. It is also noteworthy that during a static experiment, the light emitted by the LED decreases drastically over time due to ion depletion in the electrolyte when a large voltage is applied. In the present setup, the rotation continuously mixes and homogenizes the electrolyte solution, which compensates the electro-migration. For all tested conditions, the LED lighted up alternatingly once per period with a very reproducible intensity. The repetition of these events over a long enough time enables a statistic analysis of the resulting light emission output, which could be very interesting for analytical applications.

Finally, the influence of the rotation on the brightness of the LED was evaluated by comparing voltage-dependent calibration curves (Figure 4). This was done in static mode with a DC input and under stirring at $90 \mathrm{rpm}$. In that case, an acquisition time of 1 second was chosen in order to visualize the entire zone of emission of the LED during a single turn (Figure 4, bottom right inset). It appears that the overall light intensity is systematically higher when the LED is immobile by comparison to the dynamic mode where it is spinning. However, the curves are qualitatively comparable. In such a case, a quantitative comparison will be influenced by the temporal concordance between the acquisition time of the camera and the rotation rate. The shape and dimension of the region of interest (ROI) used for the treatment may also affect the brightness.

To conclude, we demonstrated that a very simple, commercially available electronic component such as a LED can be employed successfully as a magnetically-stirred bipolar electrode. This is due to the good electronic conductivity of the LED tips and also to their ferromagnetic content that enables a rotation by using a simple magnetic stirrer. When applying a continuous voltage, the rotation of the LED generates a stable alternating output for which the frequency can be controlled by the spinning rate. This was performed either with one single LED or two LEDs positioned head to tail in order to modulate in two ways the number of light emission events per second. The key advantage of this approach is to enable a very stable signal regardless the electro-migration due to a continuous and intrinsic stirring of the solution. This new concept of a magnetically-stirred bipolar electrode is particularly interesting from an fundamental point of view. However, it is also possible to envision very simple analytical applications in which a change of composition of the electrolyte will be revealed by the LED brightness. Also, this approach could be potentially adapted to different types of bipolar electrodes as long as they contain a ferromagnetic component.

A.D. acknowledges the University of Bordeaux for a PhD studentship. L.B. thanks the CNRS. This project has also been funded by the European Research Council (ERC) under the European Union's Horizon 2020 research and innovation program (grant agreement $n^{\circ} 741251$, ERC Advanced grant ELECTRA). The authors thank Prof. Wolfgang Schuhmann (RUB, Germany) for scientific discussions.

\section{Conflicts of interest}

There are no conflicts to declare.

Notes and references 
1. F. Mavré, R. K. Anand, D. R. Laws, K.-F. Chow, B.-Y. Chang, J. A. Crooks and R. M. Crooks, Anal. Chem., 2010, 82, 8766.

2. S. E. Fosdick, K. N. Knust, K. Scida and R. M. Crooks, Angew. Chem. Int. Ed., 2013, 52, 10438.

3. G. Loget, D. Zigah, L. Bouffier, N. Sojic and A. Kuhn, Acc. Chem. Res., 2013, 46, 2513.

4. L. Bouffier, V. Ravaine, N. Sojic and A. Kuhn, Curr. Opin. Colloid Interface Sci., 2016, 21, 57.

5. L. Koefoed, S. U. Pedersen and K. Daasbjerg, Curr. Opin. Electrochem., 2017, 2, 13.

6. X. Zhang, Q. Zhai, H. Xing, J. Li and E. Wang, ACS Sensors, 2017, 2, 320.

7. L. Bouffier, D. Manojlovic, A. Kuhn and N. Sojic, Curr. Opin. Electrochem., 2019, 16, 28.

8. N. Karimian, P. Hashemi, A. Afkhami and H. Bagheri, Curr. Opin. Electrochem., 2019, 17, 30.

9. P. S. Toth, M. Velický, M. A. Bissett, T. J. A. Slater, N. Savjani, A. K. Rabiu, A. M. Rakowski, J. R. Brent, S. J. Haigh, P. O'Brien and R. A. W. Dryfe, Adv. Mater., 2016, 28, 8256.

10. L. Bouffier, S. Reculusa, V. Ravaine and A. Kuhn, ChemPhysChem, 2017, 18, 2637.

11. J. Gao, S. Chen, F. AlTal, S. Hu, L. Bouffier and G. Wantz, ACS Appl. Mater. Interfaces, 2017, 9, 32405.

12. W. Gao, K. Muzyka, X. Ma, B. Lou and G. Xu, Chem. Sci., 2018, 9, 3911.

13. M. Li and R. K. Anand, Chem. Sci., 2019, 10, 1506.

14. I. Malytska, T. Doneux, M. Bougouma, A. Kuhn and L. Bouffier, J. Phys. Chem. C, 2019, 123, 5647.

15. M. R. Moghaddam, S. Carrara and C. F. Hogan, Chem. Commun., 2019, 55, 1024.

16. C. Renault, K. Scida, K. N. Knust, S. E. Fosdick and R. M. Crooks, J. Electrochem. Sci. Technol., 2013, 4, 146.

17. Q.-M. Feng, J.-B. Pan, H.-R. Zhang, J.-J. Xu and H.-Y. Chen, Chem. Commun., 2014, 50, 10949.

18. R. Liu, C. Zhang and M. Liu, Sens. Actuator B-Chem., 2015, 216, 255.

19. L. Chen, C. Zhang and D. Xing, Sens. Actuator B-Chem., 2016, 237, 308.

20. H. Liu, X. Zhou, W. Liu, X. Yang and D. Xing, Anal. Chem., 2016, 88, 10191.

21. X. Zhang, Q. Zhai, L. Xu, J. Li and E. Wang, J. Electroanal. Chem., 2016, 781, 15.

22. G. Loget and A. Kuhn, Nature Commun., 2011, 2, 535.

23. V. Eßmann, S. Voci, G. Loget, N. Sojic, W. Schuhmann and A. Kuhn, J. Phys. Chem. Lett., 2017, 8,4930 .

24. V. Eßmann, J. Clausmeyer and W. Schuhmann, Electrochem. Commun., 2017, 75, 82.

25. X. Zhang, C. Chen, J. Yin, Y. Han, J. Li and E. Wang, Anal. Chem., 2015, 87, 4612.

26. G. Loget and B. Fabre, ChemElectroChem, 2016, 3, 366.

27. J. Roche, S. Carrara, J. Sanchez, J. Lannelongue, G. Loget, L. Bouffier, P. Fischer and A. Kuhn, Sci. Rep., 2014, 4, 6705. 
28. B. Gupta, M. C. Afonso, L. Zhang, C. Ayela, P. Garrigue, B. Goudeau and A. Kuhn, ChemPhysChem, 2019, 20, 941.

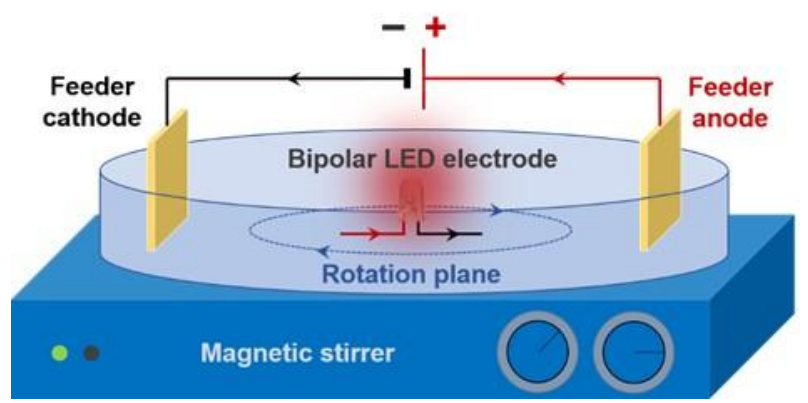

Scheme 1. Experimental setup for dual wireless magnetic and electrochemical addressing of a lightemitting diode (LED). Rotation is induced by magnetic stirring, whereas electronic actuation is driven by wireless bipolar electrochemistry (BPE).

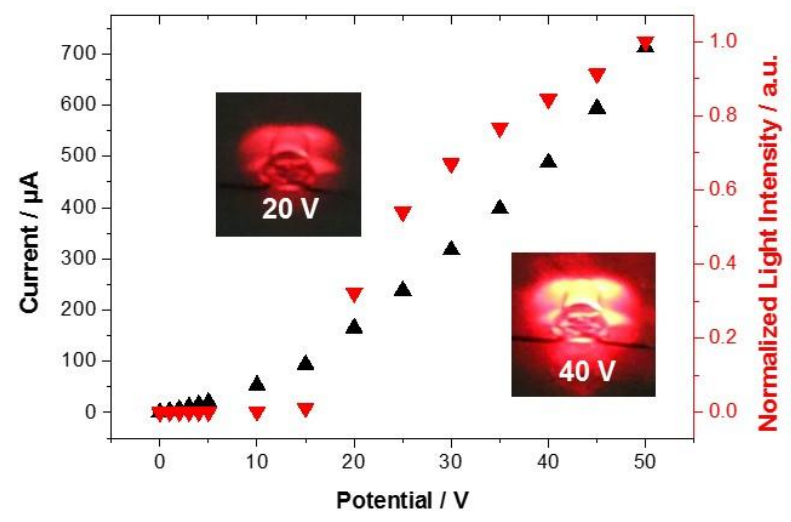

Figure 1. Bipolar electrochemical characterization of the LED used in this work. Bipolar current (black data) and light intensity (red data) versus potential difference applied to the solution. Data extracted from images (Canon EOS 70D, ISO 3200, diaphragm 6.3, exposure time $1 / 8 \mathrm{~s}$ ). Insets: Images recorded at $20 \mathrm{~V}$ and $40 \mathrm{~V}$, respectively. Electrolyte: $\mathrm{KCl} 5 \times 10^{-3} \mathrm{M}$ aqueous solution. 
A)

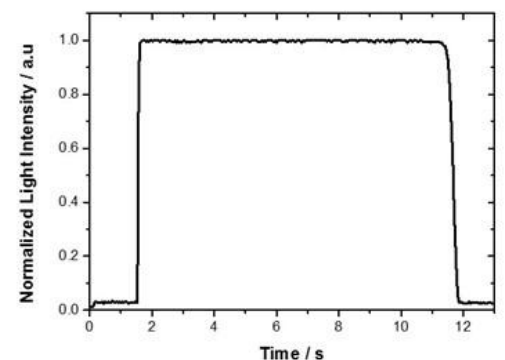

B)

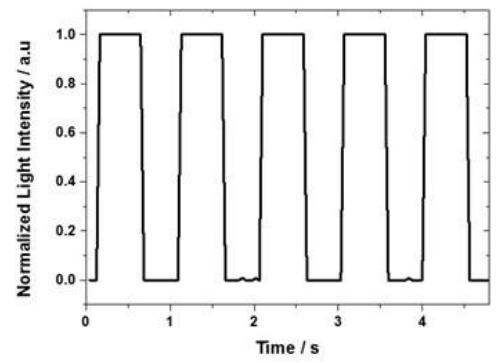

Figure 2. Time evolution of the LED intensity submitted either to a continuous input of $36 \mathrm{~V}(\mathrm{~A})$ or to an alternating input of $36 \mathrm{~V}$ pulsed at $f=1 \mathrm{~Hz}(B)$.

Electrolyte: $\mathrm{KCl} 5 \times 10^{-3} \mathrm{~mol} \mathrm{~L}^{-1}$ aqueous solution.
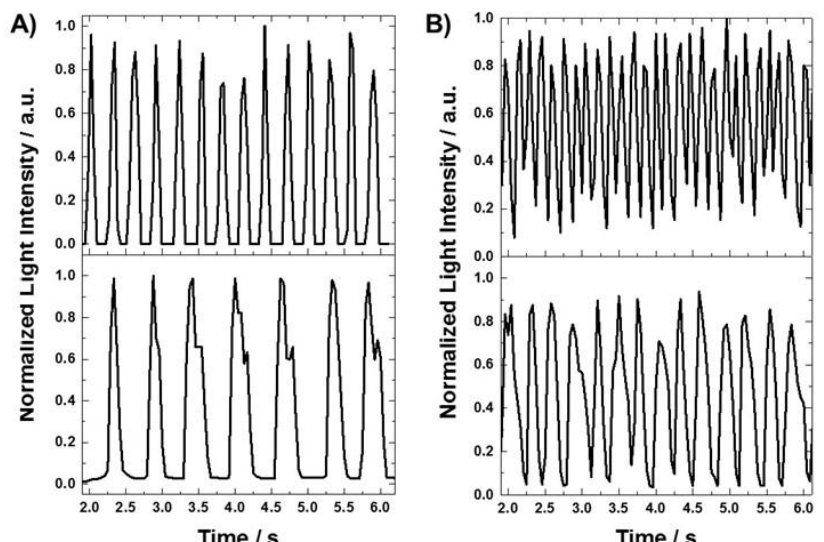

Figure 3. Time evolution of the LED intensity submitted to a DC input of $36 \mathrm{~V}$ and a rotation frequency of 100 rpm (bottom) or $200 \mathrm{rpm}$ (top). The bipolar electrode is constituted by a single LED (A) or two LEDs positioned head to tail (B). Electrolyte: $5 \times 10^{-3} \mathrm{~mol} \mathrm{~L}^{-1}$ of $\mathrm{KCl}$. 


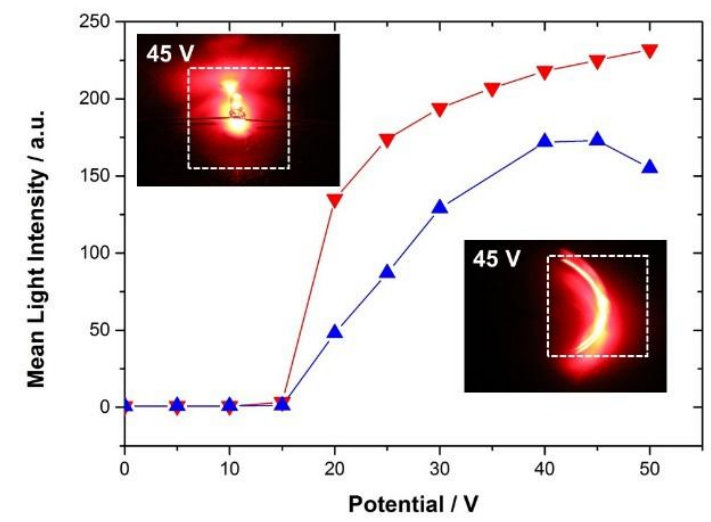

Figure 4. Comparison of the light intensity recorded in static mode (red data) and rotation mode at $90 \mathrm{rpm}$ (blue data). Data extracted from images (Canon EOS 70D, ISO 3200, diaphragm 6.3, exposure time $1 \mathrm{~s}$ ). Insets: Images recorded in each mode at $45 \mathrm{~V}$ and corresponding regions of interest (ROI) used for ImageJ treatment. Electrolyte: $\mathrm{KCl} 5 \times 10^{-3} \mathrm{~mol} \mathrm{~L}^{-1}$ aqueous solution. 